\title{
A RANDOMIZED CONTROLLED TRIAL OF MISOPROSTOL AND OXYTOCIN IN THE MANAGEMENT OF THIRD STAGE OF LABOR
}

\author{
ROKSHANA IVY ${ }^{1}$, HASMOT ARA ${ }^{2}$, KULSUM HAQ ${ }^{3}$, FARID UDDIN AHMED ${ }^{4}$
}

Senior Consultant ${ }^{1}$, Medical Officer ${ }^{2}$, Department of Obstetrics \& Gynecology, Maternal and Child Health Training Institute, Azimpur, Dhaka, Assistant Professor ${ }^{3}$, Department of Obstetrics \& Gynecology, Begum Khaleda Zia Medical College, Dhaka; Deputy Program Manager ${ }^{4}$, Directorate General of Family Planning, Dhaka

\begin{abstract}
The study was conducted to compare the effectiveness and safety of oral misoprostol with intramuscular oxytocin in the management of third stage of labor. One hundred patients were selected randomly who are expected to have vaginal delivery. Fifty patients received oral misoprostol 600 microgram and other fifty patients received oxytocin $10 \mathrm{IU}$ intramuscularly after the birth of the baby. There were no significant differences between the prevalence of postpartum hemorrhage, duration of third stage of labor, additional oxytocin requirement, manual removal of placenta and blood transfusion. About the side-effects, shivering and fever were significantly higher in misoprostol group $(p<0.001)$ and $(p<0.003)$ respectively. But there were no significant differences in other sideeffects. Oral misoprostol can be used instead of intramuscular oxytocin in the management of third stage of labor, to prevent postpartum hemorrhage, in developing countries, especially as it is administered orally and thermo stable in tropical climate.
\end{abstract}

Key words: Misoprostol, Oxytocin, Postpartum haemorrhage

(Bangladesh J Physiol Pharmacol 2008; 24(1\&2) : 14-16)

\section{INTRODUCTION}

Postpartum hemorrhage (PPH) is an important cause of maternal mortality and morbidity. In the developing world, it is estimated to account for $28 \%$ of maternal death ${ }^{1}$. Failure of the uterus to contract adequately after childbirth is the most common cause of $\mathrm{PPH}^{2}$. Active management of third stage of labor (AMTSL) reduces the risk of $\mathrm{PPH}$ by $60 \%{ }^{3}$. Active management involves giving an uterotonic drug within one minute of the birth of the baby, applying controlled cord traction when uterus is contracted and uterine massage through abdomen after placental delivery. These three interventions hasten placental delivery by increasing uterine contractions, decreasing blood loss and preventing $\mathrm{PPH}^{4}$.

Standard agents used as a component of AMTSL include oxytocin, ergometrine and a combination of oxytocin and ergometrine. However the occurrence of side-effects especially of nausea, vomiting and hypertension are a major drawback of these conventional oxytocics ${ }^{5}$. These agents are less stable in tropical

Address of Correspondence : Rokshana Ivy, Senior Consultant, Department of Obstetrics \& Gynecology, Maternal and Child Health Training Institute, Azimpur, Dhaka storage conditions, with a loss of $21-27 \%$ potency after only one month and over $90 \%$ after one year, particularly with ergometrine. These drugs are heat and light sensitive. They require parenteral administration with a sterile needle and syringe. Skilled manpower is needed for administration ${ }^{6}$.

Misoprostol is a synthetic analog of $P G E_{1}$. When given orally, it is rapidly absorbed by the gastrointestinal tract and undergoes de-estirification to its free acid, which is responsible for its clinical activity. The peak concentration and half-life of misoprostol acid, the active metabolite are 12 and 21 minutes respectively ${ }^{7}$. Misoprostol is a proven uterotonic agent ${ }^{8}$ and research using misoprostol suggests that it may be effective in the prevention of $\mathrm{PPH}^{1}$. It is inexpensive, has few sideeffects, does not require special storage condition and has a self-life of several years ${ }^{9}$.

\section{MATERIALSAND METHODS}

It was a prospective, randomized controlled trial study conducted between May, 2008 to October, 2008 in Maternal and Child Health Training Institute (MCHTI), Azimpur, Dhaka. The inclusion criteria were singleton live pregnancy at term and who are expected to have a 
vaginal delivery. Informed verbal consent was taken in early labor. When delivery was imminent i.e., at head crowning, alternate patients were selected for Misoprostol group and Oxytocin group. In Misoprostol group, 600 microgram of misoprostol was given orally after the birth of the baby and in Oxytocin group, $10 \mathrm{IU}$ of oxytocin was given intramuscularly after the birth of the baby. The exclusion criteria were multiple pregnancies, history of $\mathrm{PPH}, \mathrm{APH}$, caesarean section or myomectomy, polyhydramnios, coagulation disorder, uterine leiomyoma, precipitate labor, malpresentation, severe anaemia and known allergy to oxytocin or prostaglandin.

After delivery, a data form for each woman containing the information regarding the woman's demographic, intrapartum and postpartum characteristics was completed. The main outcome measure was the prevalence of $\mathrm{PPH}$. The results were analyzed statistically by Statistical package for the Social Sciences (SPSS) version 12 .

\section{RESULTS}

Total 100 patients were enrolled in this study. Fifty patients were randomized for oral Misoprostol 600 microgram and fifty patients for Oxytocin $10 \mathrm{IU}$ intramuscularly for the management of $3^{\text {rd }}$ stage of labor. The two groups were comparable in terms of age, gravida and gestational age (Table-I). In both the groups there were no significant differences. Similarly the out come were compared (Table-II). There were no significant differences in the prevalence of $\mathrm{PPH}$, duration of $3^{\text {rd }}$ stage of labor, additional oxytocin, requirement, retained placenta and blood transfusion. Table III showed different side effects. Incidence of shivering was $42 \%$ in Misoprostol group and $8 \%$ in Oxytocin group. It was significantly higher $(p<0.001)$ in Misoprostol group. But it was self limiting, no treatment required, only counseling was sufficient. Nausea and vomiting were in few patients but statistically not significant. Fever was $12 \%$ in Misoprostol group but in Oxytocin group no patients had fever. It was significantly higher $(\tilde{n}<0.003)$ in Misoprostol group. But it was self limiting and only one patient got paracatamol. Shivering and high temperature were transient.

Table-I

Demographic characteristics of the patients.

\begin{tabular}{lccc}
\hline Characteristics & $\begin{array}{c}\text { Misoprostol } \\
\mathrm{n}=50\end{array}$ & $\begin{array}{c}\text { Oxytocin } \\
\mathrm{n}=50\end{array}$ & $\begin{array}{c}\mathrm{P} \\
\text { value }\end{array}$ \\
\hline Maternal age in years & $23.87 \pm 4.02$ & $24.81 \pm 5.11$ & 0.321 \\
Gravida Primigravida & $11(22 \%)$ & $20(40 \%)$ & 0.546 \\
\multicolumn{1}{c}{ Multigravida } & $39(78 \%)$ & $30(60 \%)$ & 0.478 \\
Gestational age & $38.35 \pm 1.13$ & $38.08 \pm 3.31$ & 0.596 \\
in weeks & & & \\
\hline
\end{tabular}

January / July 2008
Table-II

Comparison of outcome between Misoprostol and Oxytocin treated groups

\begin{tabular}{lccc}
\hline Out come & $\begin{array}{c}\text { Misoprostol } \\
\mathrm{n}=50\end{array}$ & $\begin{array}{c}\text { Oxytocin } \\
\mathrm{n}=50\end{array}$ & $\begin{array}{c}\mathrm{P} \\
\text { value }\end{array}$ \\
\hline PPH & $02(4 \%)$ & $01(2 \%)$ & 0.554 \\
Duration of $3^{\text {rd }}$ stage & $7.51 \pm 4.51$ & $6.21 \pm 2.21$ & 0.088 \\
in minutes & & & \\
Additional oxytocin & $04(8 \%)$ & $01(2 \%)$ & 0.155 \\
Retained placenta & $01(2 \%)$ & 00 & 0.237 \\
\hline
\end{tabular}

Table-III

Comparison of side effects between Misoprostol and Oxytocin treated groups

\begin{tabular}{lccc}
\hline Side-effects & $\begin{array}{c}\text { Misoprostol } \\
\mathrm{n}=50\end{array}$ & $\begin{array}{c}\text { Oxytocin } \\
\mathrm{n}=50\end{array}$ & $\begin{array}{c}\mathrm{P} \\
\text { value }\end{array}$ \\
\hline Shivering & $21(42 \%)$ & $04(8 \%)$ & 0.001 \\
Nausea & $04(8 \%)$ & $04(8 \%)$ & 1.000 \\
Vomiting & $02(4 \%)$ & 00 & 0.093 \\
Fever & $06(12 \%)$ & 00 & 0.003 \\
\hline
\end{tabular}

\section{DISCUSSION}

In this study, 600 microgram misoprostol was given orally in misoprostol group and $10 \mathrm{IU}$ oxytocin was given intramuscular in oxytocin group for the management of $3^{\text {rd }}$ stage of labor. With Misoprostol the prevalence of $\mathrm{PPH}$, need for further therapeutic oxytocin and the length of $3^{\text {rd }}$ stage of labor were compared with results obtained with oxytocin. These findings suggest that misoprostol may be an alternate to conventional oxytocics in the tropics for AMTSL. Here intramuscular oxytocin is used as it is the current management recommended by $\mathrm{WHO}^{10}$. The prevalence of $\mathrm{PPH}$ in misoprostol group and in oxytocin group were $4 \%$ and $2 \%$ respectively which is comparable to another study e.g., $3.8 \%$ and $2.63 \%$ respectively ${ }^{11}$. In both the studies, there was no significant difference in the prevalence of $\mathrm{PPH}$ in the study groups. In the present study, the duration of $3^{\text {rd }}$ stage of labor in misoprostol group was $7.51 \pm 4.51$ and in oxytocin group $6.21 \pm 2.21$ in minutes, which were similar in another study $^{12}$ showed 8 minutes versus 9 minutes but both studies showed no significant difference between two groups. The present study showed no statistical differences in terms of additional oxytocin requirement, retained placenta and blood transfusion in both groups, which is similar to other studies ${ }^{11,12,13}$. In this study, shivering was significantly higher $(p<0.001)$ in Misoprostol group than Oxytocin group. Incidence of shivering was little higher in another study, but that was 
self limiting, no treatment required, only counseling was sufficient ${ }^{14}$. Shivering is regarded as nuisance rather morbidity. Nausea and vomiting were in few patients but statistically not significant. Fever was $12 \%$ in Misoprostol group but in Oxytocin group with no patients. It was significant higher than oxytocin group, which was also observed in other studies ${ }^{11,12,14}$. The occurrence of shivering and elevated temperature with Misoprostol may be related to prostaglandin E1 effect on the thermoregulatory center ${ }^{15}$.

The study demonstrated that oral misoprostol and intramuscular oxytocin appear to be equally effective in the prevention of $\mathrm{PPH}$. Shivering and transient pyrexia occurred more frequently with misoprostol. Both were self-limiting and did not require any intervention, only one patient got paracatamol for fever. Misoprostol has been shown to have more advantages as an alternative therapy including its low cost, oral administration, easily stored at room temperature, long shelf-life of several years and minimal side-effects. Because of the great potential of misoprostol in its use in $3^{\text {rd }}$ stage of labor, it can be used instead of oxytocin in developing countries especially as it is administered orally and thermo stable in tropical conditions. Further large scale randomized controlled trial is required to confirm these results.

\section{REFERENCES}

1. Walder J. Misoprostol: preventing PPH. Modern Midwife 1997; 7(9): 23-7.

2. Mathews M, et al. Saving Women's lives: evidence based recommendations for the prevention of postpartum haemorrhage, April 2007; Bulletin of WHO: 85(4).

3. Sariano D, Dulitghi M, et al. A prospective cohort study of oxytocin plus ergometrine compared with oxytocin alone for prevention of PPH. Br J Obs Gyn 1996; 103(11): 106873.
4. Program for Appropriate Technology in Health (PATH). Preventing postpartum haemorrhage: managing the third stage of labor. Out look 2001; 19: 1-8.

5. Oboboro VO, Taboewei TO. A randomized controlled trial of misoprostol versus oxytocin in the active management of the third stage of labour. J Obs Gyn 2003; 23(1): 13-16.

6. Hogerzeil HV, Walka GJA, De Goeje MJ. Stability of Injectable oxytocics in tropical climates, 1993. World Health Organization, Geneva.

7. Jeferson H, Jr. Andrew K. Current trends in cervical ripening and labor induction, August. Am Acad Fam Phy 1999: 1-10.

8. Fletdron $\mathrm{H}$, Mitchlles S, et al. Intravaginal misoprostol versus dinoproston as cervical ripening and labour inducing agent. Obs Gynaecol 1994; 83: 244-247.

9. Kararli TT, Catalor OT, Necdhar TE, et al. Mechanism of misoprostol stabilization in hydroxypropyl methylcellulose. Adv Exp Med Bio 1991; 302: 275-289.

10. World Health Organization (1991a) Maternal Mortality: A Global Fact book, pp 3-16. World Health Organization, Geneva.

11. Sultana N, Khatun M. Misoprostol versus oxytocin in the active management of the third stage of labor. Journal of BCPS 2007; 25: 73-76.

12. Surbek DV, Fehr PH, Hosli I, et al. Oral misoprostol for third stage of labor: a randomized placebo controlled trial. Obs Gynaecol 1999; 94(2): 255-8.

13. Gulmezoglu AM, Villar J, Ngoc NT, et al. WHO multicenter randomized trial of misoprostol in the management of third stage of labour. Lancet 2001; 358: 689-695.

14. El-Refacy $\mathrm{H}$, O'Brian $\mathrm{P}$, et al. Randomized placebo controlled trial of oral misoprostol in the third stage of labour. Br J Obstet Gynaecol 1998; 105: 971-975.

15. Creinin M.D, Vittinghoff E, et al. Medical abortion with oral methotraxate and vaginal misoprostol. Br J Obs Gyn 1997; 90: 611-616 